\title{
Spinal cord injury as a trigger to develop periodic leg movements during sleep: an evolutionary perspective
}

\author{
Lesão medular como gatilho para desenvolver movimentos periódicos das pernas durante \\ o sono: uma perspectiva evolutiva
}

Susana Cristina Lerosa Telles, Rosana S. Cardoso Alves, Gerson Chadi

\begin{abstract}
The primary trigger to periodic limb movement (PLM) during sleep is still unknown. Its association with the restless legs syndrome (RLS) is established in humans and was reported in spinal cord injury (SCI) patients classified by the American Spinal Injury Association (ASIA) as A. Its pathogenesis has not been completely unraveled, though recent advances might enhance our knowledge about those malfunctions. PLM association with central pattern generator (CPG) is one of the possible pathologic mechanisms involved. This article reviewed the advances in PLM and RLS genetics, the evolution of CPG functioning, and the neurotransmitters involved in CPG, PLM and RLS. We have proposed that $\mathrm{SCl}$ might be a trigger to develop PLM.
\end{abstract}

Key words: nocturnal myoclonus syndrome, restless legs syndrome, spinal cord regeneration.

\section{RESUMO}

O gatilho principal para o desenvolvimento de movimentos periódicos dos membros (MPM) durante o sono ainda é desconhecido. A associação entre o MPM e a síndrome das pernas inquietas (SPI) em seres humanos já foi previamente estabelecida e relatada em pacientes com lesão medular (LM), classificados pela American Spinal Injury Association (ASIA) como A. A patogênese do MPM não foi completamente desvendada, apesar de avanços recentes poderem ampliar o conhecimento sobre essas disfunções. Um dos possíveis mecanismos patológicos envolvidos é o gerador de padrão central (GPC). Este artigo revisou os avanços na genética do MPM e da SPI, a evolução do funcionamento do GPC e os neurotransmissores relacionados ao GPC, ao MPM e à SPI. Foi proposta a hipótese de que a LM poderia ser um gatilho para deflagrar os MPM.

Palavras-Chave: síndrome da mioclonia noturna, sindrome das pernas inquietas, regeneração da medula espinal.

The periodic limb movement (PLM) disorder is characterized by periodic episodes of repetitive and highly stereotyped limb movements, which occur during sleep, and by clinical sleep disturbance that cannot be accounted for by another primary sleep disorder ${ }^{1}$. They consist of the big toe extension in combination with partial flexion of the ankle and, sometimes, hip (Fig 1). Similar movements can occur in the upper limbs. This occurrence in spinal cord injury (SCI) patients ${ }^{2}$ (Fig 2) suggests the spinal origin of those movements, which could be due to the disruption of REM-related inhibitory spinal pathways, producing the disconnection or disinhibition of a spinal generator, which is a kind of local pacemaker ${ }^{3}$.
Restless legs syndrome (RLS) is a sensorimotor disorder frequently related to PLM and was recently reported in SCI patients ${ }^{2}$. It is characterized by a complaint of a strong, nearly irresistible, urge to move the legs, which is made worse by rest (lying or sitting) and is at least partially and temporarily relieved by walking or moving the legs. The relief is usually immediate. The urge to move the legs worsens in the evening and at night ${ }^{1}$.

Scientific reviews have addressed the probable central pattern generator (CPG) in SCI patients and its outcome to rehabilitation. We based this review on an evolutionary perspective of CPG development from invertebrates to mammals, in order to point to the probable CPG action in humans during PLM.

\footnotetext{
Neuroregeneration Center, Experimental Neurology, Department of Neurology, School of Medicine, Universidade de São Paulo, São Paulo SP, Brazil. Correspondence: Susana Cristina Lerosa Telles; Avenida Doutor Arnaldo 455 / 2.115; 01246-903 São Paulo SP - Brasil; E-mail: telles.susana@gmail.com Support: Coordenação de Aperfeiçoamento de Pessoal de Nivel Superior (CAPES). 


\section{CENTRAL PATTERN GENERATOR} EVOLUTIONAL ASPECTS

Graham Brown proposed the following: "when the geographical relations between animal and environment remained adverse, there would occur a local asphyxia of the efferent neuron - the primitive centre - and a motor activation of the limbs, even if uncoordinated, would serve to drive the animal to a new region in which the deficiency of nutritive materials would be compensated". This statement can be interpreted as a defense mechanism in case of any movement malfunction causing spasticity, which would cause a poor motor coordination, but would elicit movements so that the animal could search for food ${ }^{4}$. As evolution proceeded and the primitive nervous system became enclosed with the CPG inside, the environment local asphyxia would no longer directly affect the nerves centers and its place would be taken by the blood stimulus (hunger) that acts even in higher forms ${ }^{4}$.

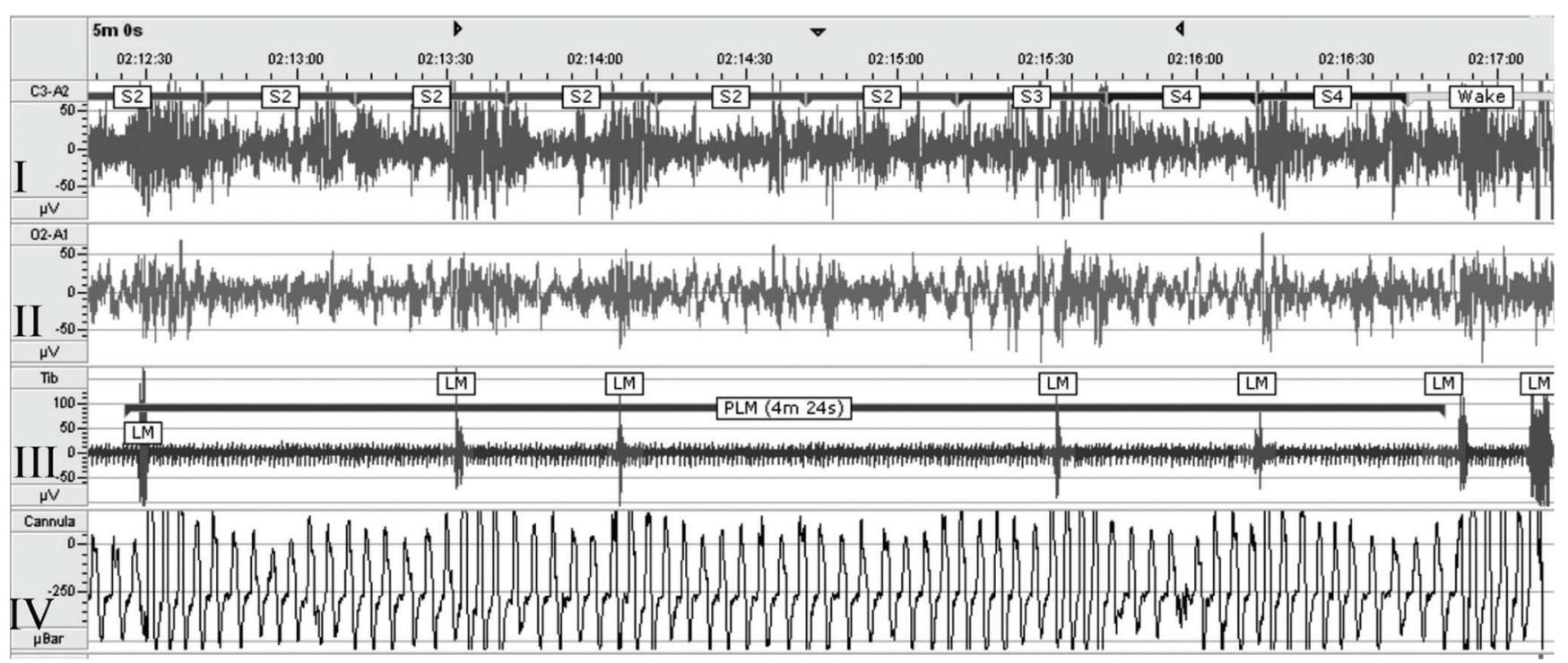

Fig 1. Periodic leg movements cluster. Five-minute polysomnographic recording of a 28 years-old female volunteer with restless leg syndrome, without diurnal somnolence or any other health problems in order to demonstrate periodic leg movements cluster. The movements took place during stages 2, 3, and 4 of nonrapid eye movement sleep. (I) Electroencephalogram in central derivation showing stage 2 (S2), 3 (S3), 4 (S4), and wake; (II) electroencephalogram in occipital derivation; (III) tibialis anterior electromyogram showing leg movements, which are characteristic of PLM that last four minutes and 24 seconds; (IV) airway derivation showing regular airway breathing during the periodic leg movement event.

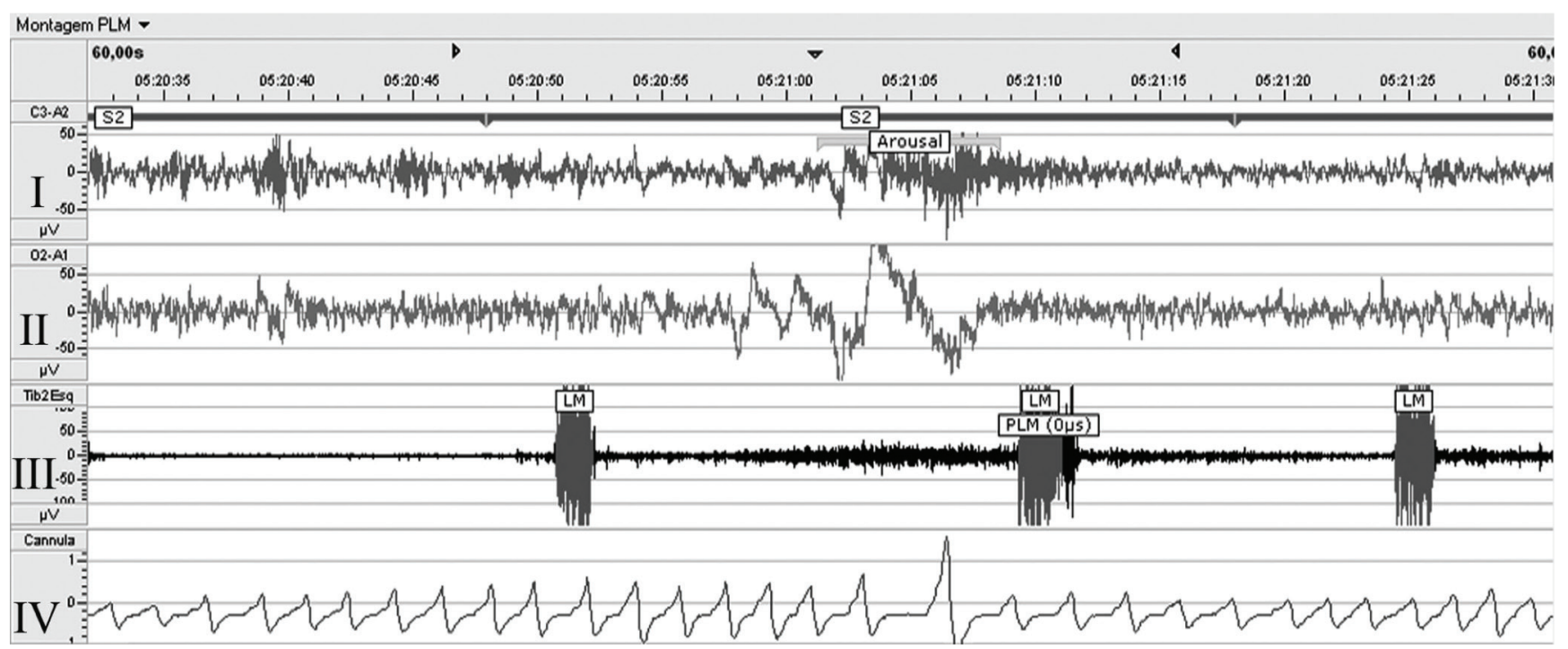

Fig 2. Periodic leg movements cluster and arousals. Polysomnographic recording of a 21 years-old spinal cord injury male patient with periodic leg movements, severe restless legs syndrome, and diurnal somnolence. In this case, the movements took place during stage 2 (S2) of nonrapid eye movement sleep and were associated with arousals. (I) Electroencephalogram in central derivation C3-A2; (II) electroencephalogram in occipital derivation O2-A1; (III) electromyogram showing leg movements, which are characteristic of PLM; (IV) airway derivation showing normal breathing during the events. 
The highest forms have similar CPG, but it is difficult to explain how more complex patterns made by many different joints with multiple movements would be controlled and executed by an isolated system. Most of all, it would hardly come from Brown's CPG model alone. Many researches point out more complex systems in invertebrates and vertebrates.

One of the first CPG models can be found among the invertebrates. The stomach of the crab is composed of striated muscles that are controlled by a CPG, located inside the stomatogastric ganglion. It is controlled by extrinsic neuromodulatory substances, which can change or activate specific motor patterns. The most important neurotransmitters in this case are serotonin for neuromodulation and acetylcholine for a faster neurotransmission. On the other hand, the Tritonia diomedia mollusk uses only serotonin to activate its escape swim CPG, when attacked by a predatory starfish ${ }^{5}$.

Also in the vertebrates, the neuromodulators are responsible for behavioral flexibility in the CPGs. There are two major mechanisms by which those neuromodulatory influences alter the function of the CPG: the combination of intrinsic membrane properties, such as the ability to generate plateau potentials or post-inhibitory rebound, or interactions between members of the pattern generator circuits ${ }^{5}$.

In vertebrates, the CPG is activated by interactions between glycine and glutamate. The external modulations are made by monoamines, glutamines, and peptides. Also, multiple ion channels and signal transduction mechanisms in pre- and post-synaptic cellular compartments play a role in rhythm generation. They are controlled by co-activation of $\alpha$-amino-3-hydroxy-5-methylisoxazole-4-propionic acid (AMPA) and N-methyl d-aspartate (NMDA) receptors by glutamate release from descending fibers, such as the reticulospinal system ${ }^{6}$. For instance, in tadpoles, swimming requires continuous excitatory output that comes from hindbrain neurons, which excite one another through the co-release of glutamate and acetylcholine, causing persistent activity in the entire group of neurons?

The inhibition that occurs in Brown's model is elicited by glycine in all preparations of vertebrates. Gammaaminobutyric acid (GABA) inhibits the CPG, and nitric acid acts as modulator of the swimming pattern and of the release of other modulators, such as noradrenalin. This neuromodulator is released by the ventral horns and it is attached to glycinergic receptors ${ }^{7}$. GABA receptors play a similar role in some cases ${ }^{6}$. The mechanism for hyperpolarization is also shared among mammalian species, turtles, and lampreys. During the plateau depolarization, $\mathrm{Ca}^{2+}$ enters the cytosol. During activity-dependent-release of glutamate, NMDA and metabotropic glutamate receptors are activated. NMDA receptor activation coupled with depolarization allows a direct entry of $\mathrm{Ca}^{2+}$ at the synapse ${ }^{8,9}$.

The complexity increases in the control of mammalian respiratory system. The site of pattern generator is called Bötzinger complex. In such place, the CPGs are controlled by two kinds of pacemaker neurons, with bursting sustained by different electrical currents: sodium (cadmium insensitive pacemaker) and a nonspecific $\mathrm{Ca}^{2+}$ dependent cation current (cadmium sensitive pacemakers), in addition to extensive synaptic interactions. This system is subjected to neuromodulation by several different amines and peptides, such as serotonin, norepinephrine, substance P, and acetylcholine functioning through muscarinic acetylcholine receptors ${ }^{9}$.

Mammalian spinal cord functioning is still not understood. By means of genetic techniques, many neurons have been identified as being part of an alleged CPG in mice. Five classes of progenitor cells give rise to motoneurons, and four others of ventrally located interneurons form reflex or locomotor circuits in the adult mouse ${ }^{10}$.

Vilensky and O'Connor ${ }^{11}$ reviewed the literature on stepping in nonhuman and human primates and discussed their experiment of trying to elicit steps in a squirrel monkey with complete transected spinal cord (level T8), based on treadmill training. They pointed out the high probability that locomotion in monkeys is based on spinal cord CPG, but different species might require other types of stimulation to turn the CPG on. It is a matter of understanding that the primate must have full body support, differently from spinalized cats or dogs, which are able to support their body after a spinal cord lesion. It can be assumed that the human CPG would be even harder to stimulate.

There are important neuroanatomical changes in primate evolution. Heffner and Masterton ${ }^{12}$ found a correlation of two factors and increased digital dexterity: a reduction of the number of synapses between the neocortex and the spinal motoneurons innervating the digits, and an extension of direct neocortical control beyond the cervical enlargement. Those neuroanatomical characteristics can be translated into the theory of increasing encephalization across the evolution. The increase in finger-motor coordination has led to higher survival chance for primates. The consequence was the spinal cord submission to neocortex in a larger scale than what is seen in other species.

\section{PERIODIC LIMB MOVEMENT AND RESTLESS LEGS SYNDROME GENETICS}

There is strong evidence about a presumed hereditary component of PLM. Five loci (12, 14, 9, 2, and 20 p) have already been described ${ }^{13}$. A recent article showed the association between a sequence variant in chromosome $6 \mathrm{p}$ with PLM in distinct Icelandic and American cohorts of subjects with RLS and their families ${ }^{14}$. A simultaneous report by Winkelman ${ }^{15}$ showed an association between the same sequence variant and two additional single nucleotide polymorphisms in German and Canadian cohorts with RLS. Thus, PLM could serve as a heritable biologic marker or endophenotype for the RLS. 


\section{PERIODIC LIMB MOVEMENT IN SPINAL CORD INJURY PATIENTS}

Since the first neural CPG theory proposed by Graham Brown through his experiments on cats ${ }^{4}$, the most compelling evidence of human CPG is the occurrence of PLM in SCI patients. Telles et al. ${ }^{2}$ reported the presence of RLS and PLM in the American Spinal Injury Association (ASIA) A patients. In this study, 24 patients were submitted to a full night polysomnography and were assessed with Epworth Sleepiness Scale and an adapted form of International RLS Scale Rating Scale (IRLS Rating Scale). The Control Group (CG) was composed of 16 subjects, $50 \%$ of each sex, and ages: $24.38 \pm 4$ years-old. The SCI Group (SCIG) was composed of eight subjects ( $29 \pm 5$ years-old) with a complete SCI (ASIA A) of about three and a half years of duration, $100 \%$ males. The result was $100 \%$ of the SCIG had RLS compared to $17 \%$ in the CG $(\mathrm{p}<0.0001)$. SCIG had $18.11 \pm 20.07$ of PLM index, while the CG had $5.96 \pm 11.93$ ( $\mathrm{p}=0.01$ ).

There are many other theories regarding PLM in noninjured patients. Summarizing, it is not known whether PLM would be a consequence of the absence of superior efferences to the spinal cord, which would cause an increase in the excitability of the motoneurons, or if it is a primary phenomena coming from a generator located inside the human spinal cord. If its origin is in the superior central nervous system, it is not known if the abnormal movements would be correlated with the sleep stage ${ }^{3}$, relative concentration of iron in the red nucleus ${ }^{16}$, and lack of iron in the blood caused by anemia or central neurotransmitters disorders ${ }^{17}$. If its origin is intrinsic to the spinal cord, the action of the neurotransmitters in the spinal cord might be one of the causes of PLM.

\section{NEUROTRANSMITTERS INVOLVED IN PERIODIC LIMB MOVEMENT AND IN THE RESTLESS LEGS SYNDROME}

Considering the previous explanations of spinal cord physiology in the vertebrates, animal models of PLM provide a promising way to study neuronal connections that lie within the spinal cord. Ondo et al. ${ }^{18}$ reviewed animal models for RLS and PLM caused by iron deprivation and destruction of the A11 diencephalic spinal tract. They specifically discussed RLS 6-hydroxydopamine rat model with and without iron deficiency and dopamine D3 receptor knockout mice. For PLM, they discussed the effect of haloperidol, a dopamine antagonist, in rats. They concluded that even though the RLS animal models might help in the evaluation of the involvement of dopaminergic action or iron depletion in RLS, this is not a perfect model, since it comes without the clinical sensory components that characterize the syndrome in humans ${ }^{18}$. Since PLMs are seen as behavioral markers for RLS in animal models, those models might be closer to human PLM itself than to human RLS.

Esteves et al. ${ }^{19}$ described a mouse animal model in ten rats subjected to $\mathrm{T} 9$ lesions. There were four different types of lesion: Group 0, with no histopathological alterations (SHAM Group); Group I, predominantly affecting central part of dorsal column; Group II, predominantly the entire dorsal column; Group III, affecting mainly the half spinal cord, including the whole dorsal column; and Group IV, almost all the spinal cord. Their results showed that 10 out of 11 rats developed limb movements during sleep, while the SHAM Group presented no limb movements during the experiment. Their conclusions were that these movements are probably generated by a spinal CPG, without the involvement of cortical inputs. This model might help to found out spinal mechanisms responsible for PLM in animals.

In humans, there are major controversies with regard to the localization of the neural structures involved in the pathologic process of RLS, however there is most likely a major contribution of the spinal cord. Bara-Jimenez et al. ${ }^{20}$ studied the flexion reflex of patients with primary RLS by electrically stimulating the plantar nerve. They found a facilitation of the late component of flexor reflex afferent (FRA), indicating hyperexcitability of motoneurons in this condition. Included in the FRA are high-threshold muscle, joint, and cutaneous afferents. They also noted that the late components shared several features with PLM. Those studies suggest the presence of a CPG for the periodic motor manifestations of RLS. According to the authors, this CPG might be facilitated by the suppression of or decrease in supraspinal inhibitory inputs. The FRA would be the tool through which the spinal CPG would act and would be responsible for the relief caused by movement in RLS ${ }^{21}$.

\section{FINAL REMARKS}

A question can be raised: is PLM an evolutional trace of ancient CPGs instead of pathology in itself? An answer should take into consideration the high prevalence of PLM in SCI. In this condition, the encephalization that distinguishes the human species is compromised, and the spinal cord and all its structures are no longer submitted to the neocortex. This leads to many neurological features that characterize SCI injuries, such as alterations in tonus, muscular strength, sensation, and others. Those are neuroplasticity-related events that like in brain injuries ${ }^{22}$ lead to neurological function deterioration. Maybe in those cases, PLM is a manifestation of the release of the spinal generator resulting in leg movements.

The fact that there is a genetic component in PLM does not exclude the possibility of this phenomenon being 
generated by CPG. From an evolutionary perspective, one could suppose that the SCI and the consequent release of the human CPG would be the necessary triggers to develop PLM. The important point is that one theory does not exclude the other. There might be simultaneous or multiple events that lead to PLMs, not only in SCI patients, but also in all others that present this disturbance. This knowledge may in the future be another tool to deal with SCI rehabilitation.

\section{References}

1. American Academy of Sleep Medicine. International classification of sleep disorders, revised: diagnostic and coding manual. Chicago (Illinois): The Academy; 2001.

2. Telles SC, Alves RC, Chadi G. Periodic limb movements during sleep and restless legs syndrome in patients with ASIA A spinal cord injury. J Neurol Sci 2011;303:119-123.

3. Dickel MJ, Renfrow SD, Moore PT, Berry RB. Rapid eye movement sleep periodic leg movements in patients with spinal cord injury. Sleep 1994;17:733-738.

4. Brown TG. On the nature of the fundamental activity of the nervous centres; together with an analysis of the conditioning of rhythmic activity in progression, and a theory of the evolution of function in the nervous system. J Physiol 1914;48:18-46.

5. Katz PS. Comparison of extrinsic and intrinsic neuromodulation in two central pattern generator circuits in invertebrates. Exp Physiol 1998;83:281-292.

6. Alford S, Schwartz E, Viana di Prisco G. The pharmacology of vertebrate spinal central pattern generators. Neuroscientist 2003;9:217-228.

7. Dickinson PS. Neuromodulation of central pattern generators in invertebrates and vertebrates. Curr Opin Neurobiol 2006;16:604-614.

8. Kettunen P, Krieger P, Hess D, El Manira A. Signaling mechanisms of metabotropic glutamate receptor 5 subtype and its endogenous role in a locomotor network. J Neurosci 2002;22:1868-1873.

9. Krieger P, Grillner S, El Manira A. Endogenous activation of metabotropic glutamate receptors contributes to burst frequency regulation in the lamprey locomotor network. Eur $J$ Neurosci 1998;10:3333-3342.

10. Gordon IT, Whelan PJ. Deciphering the organization and modulation of spinal locomotor central pattern generators. $J$ Exp Biol 2006;209:2007-2014.

11. Vilensky JA, O'Connor BL. Stepping in humans with complete spinal cord transections: a phylogenetic evaluation. Motor Control 1997;1:284-292.

12. Heffner RS, Masterton RB. The role of the corticospinal tract in the evolution of human digital dexterity. Brain Behav Evol 1983;23:165-183.

13. Pichler I, Hicks AA, Pramstaller PP. Restless legs syndrome: an update on genetics and future perspectives. Clin Genetics 2008;73:297-305.

14. Winkelmann J, Muller-Myhsok B, Wittchen HU, et al. Complex segregation analysis of restless legs syndrome provides evidence for an autosomal dominant mode of inheritance in early age at onset families. Ann Neurol 2002;52:297-302.

15. Winkelman JW. Periodic limb movements in sleep - endophenotype for restless legs syndrome? N Engl J Med 2007;357:703-705.

16. Allen RP, Barker PB, Wehrl F, Song HK, Earley CJ. MRI measurement of brain iron in patients with restless legs syndrome. Neurology 2001;56:263-265.

17. Barriere G, Cazalets JR, Bioulac B, Tison F, Ghorayeb I. The restless legs syndrome. Prog Neurobiol 2005;77:139-165.

18. Ondo WG, Zhao HR, Le WD. Animal models of restless legs syndrome. Sleep Med 2007;8:344-348.

19. Esteves AM, de Mello MT, Lancellotti CL, Natal CL, Tufik S. Occurrence of limb movement during sleep in rats with spinal cord injury. Brain Res 2004;1017:32-38.

20. Bara-Jimenez W, Aksu M, Graham B, Sato S, Hallett M. Periodic limb movements in sleep: state-dependent excitability of the spinal flexor reflex. Neurology 2000;54:1609-1616.

21. Paulus W, Schomburg ED. Dopamine and the spinal cord in restless legs syndrome: does spinal cord physiology reveal a basis for augmentation? Sleep Med Rev 2006;10:185-196.

22. Cecatto RB, Chadi G. The importance of neuronal stimulation in central nervous system plasticity and neurorehabilitation strategies. Funct Neurol 2007;22:137-143. 